\title{
EFeitos da AdubaçÃo Nitrogenada EM Cobertura sobre a Seletividade de Herbicidas à Cultura do Milho ${ }^{1}$
}

\author{
Effects of Cover Nitrogen Fertilization on Herbicide Selectivity in Corn
}

\author{
NICOLAI, M. ${ }^{2}$, LÓPEZ OVEJERO, R.F. ${ }^{2}$, CARVALHO, S.J.P. ${ }^{3}$, MOREIRA, M.S. ${ }^{3}$ e \\ CHRISTOFFOLETI, P.J. ${ }^{4}$
}

\begin{abstract}
RESUMO - O objetivo deste trabalho foi avaliar os efeitos da adubação nitrogenada de cobertura sobre a seletividade dos herbicidas aplicados em pós-emergência na cultura do milho (Zea mays). Para isso, foram conduzidos dois experimentos. Em um deles utilizou-se uréia incorporada (67,5 $\left.\mathrm{kg} \mathrm{N} \mathrm{ha}^{-1}\right)$ como fonte nitrogenada e, no outro, sulfato de amônio (62 $\mathrm{kg} \mathrm{N} \mathrm{ha}^{-1}$ ) a lanço. Os tratamentos foram conseqüência da combinação fatorial entre quatro níveis do fator herbicida: mesotrione $\left(144 \mathrm{~g} \mathrm{ha}^{-1}\right)+$ atrazine $\left(1.500 \mathrm{~g} \mathrm{ha}^{-1}\right)$, foransulfuron + iodosulfuron $\left(45+3 \mathrm{~g} \mathrm{ha}^{-1}\right)$, nicosulfuron $\left(20 \mathrm{~g} \mathrm{ha}^{-1}\right)+$ atrazine $\left(1.500 \mathrm{~g} \mathrm{ha}^{-1}\right)$ e testemunha capinada; $\mathrm{e}$ quatro níveis do fator época de adubação: 7,3 e 0 dias antes e 7 dias após a aplicação dos herbicidas (DAA), perfazendo 16 tratamentos. Avaliaram-se: fitotoxicidade aos 7, 14, $21 \mathrm{e}$ 28 DAA, altura das plantas de milho no florescimento, massa de 1.000 grãos e rendimento. Não foi detectada a interação significativa entre os herbicidas e as fontes nitrogenadas utilizadas para nenhuma das variáveis em estudo. Embora efeitos fitotóxicos tenham sido observados, não houve diferenças estatísticas para altura de planta, massa de 1.000 grãos ou rendimento.
\end{abstract}

Palavras-chave: manejo, nitrogênio, sulfoniluréia, mesotrione, fitotoxicidade.

\begin{abstract}
The objective of this work was to evaluate the effects of cover nitrogen fertilization on selectivity of post-emergence applied herbicides in corn (Zea mays). Thus, two experiments were conducted: in one of them, urea $\left(67.5 \mathrm{~kg} \mathrm{ha}^{-1}\right)$ was used as nitrogen source and in the other ammonium sulfate (62 $\mathrm{kg} \mathrm{N} \mathrm{ha}$ ) was used. The treatments consisted of a factorial combination of four levels of herbicide: mesotrione $\left(144 \mathrm{~g} \mathrm{ha}^{-1}\right)+$ atrazine $\left(1,500 \mathrm{~g} \mathrm{ha}^{-1}\right)$, foransulfuron + iodosulfuron $\left(45+3 \mathrm{~g} \mathrm{ha}^{-1}\right)$, nicosulfuron $\left(20 \mathrm{~g} \mathrm{ha}^{-1}\right)+$ atrazine $\left(1,500 \mathrm{~g} \mathrm{ha}^{-1}\right)$ and handweeded checks; and four levels fertilization timing: 7, 3 and 0 days before and 7 days after herbicide application (DAA), totalizing 16 treatments. Phytotoxicity at 7, 14, 21 and 28 DAA, height at flowering, mass of 1,000 grains and crop yield were evaluated. No significant interaction was detected between the herbicides and the nitrogen sources used for the variables evaluated. Although phytotoxicity effects were observed, no significant differences were found for plant height, mass of 1,000 grains or crop yield.
\end{abstract}

Keywords: management, nitrogen, sulfonylurea, mesotrione, phytotoxicity.

1 Recebido para publicação em 11.10.2005 e na forma revisada em 5.5.2006.

Parte da dissertação do primeiro autor apresentada à ESALQ para obtenção do título de Mestre em Agronomia. Este trabalho foi parcialmente financiado pela FAPESP.

2 Eng.-Agr., doutorando em Fitotecnia, Escola Superior de Agricultura “Luiz de Queiroz" - ESALQ/USP, $<$ marcelon@esalq.usp.br>; ${ }^{3}$ Eng.-Agr., mestrando em Fitotecnia - ESALQ/USP, <sjpcarvalho@ yahoo.com.br>; ${ }^{4}$ Professor Associado do Departamento de Produção Vegetal - ESALQ/USP, Caixa Postal 09, 13419-900 Piracicaba-SP, <pjchrist@esalq.usp.br>.

Planta Daninha, Viçosa-MG, v. 24, n. 2, p. 279-286, 2006 


\section{INTRODUÇÃO}

Na cultura do milho (Zea mays), a intensidade da interferência das plantas daninhas é variável, em função da época de ocorrência, da densidade populacional e das espécies presentes no local (Zagonel et al., 2000), de modo que a adoção de medidas de controle é essencial para assegurar a produtividade.

Historicamente, o manejo de plantas daninhas mais utilizado nas culturas agrícolas baseava-se em capinas manuais e no cultivo mecânico das entrelinhas, com reconhecida eficiência (Abdin et al., 2000; Wilson, 1993). No entanto, devido ao desenvolvimento do método químico de controle de plantas daninhas, a aplicação de herbicidas tornou-se freqüente, sobretudo em conseqüência de sua eficácia, conveniência e viabilidade de custos (Abdin et al., 2000; Jakelaitis et al., 2005).

Christoffoleti \& Mendonça (2001) ressaltam que a aplicação de herbicidas em pósemergência da cultura do milho surgiu e se fortaleceu recentemente como uma ferramenta para o controle de plantas daninhas. Contudo, a adoção desses agroquímicos, principalmente das sulfoniluréias, necessita da observação de alguns fatores, como o híbrido utilizado, o estádio fenológico da cultura no instante da aplicação e o intervalo entre a aplicação do herbicida e a do inseticida organofosforado ou da adubação nitrogenada de cobertura, que, quando negligenciados, podem interferir em sua seletividade e causar fitotoxicidade à cultura (López Ovejero et al., 2003).

A aplicação de nitrogênio (N) em cobertura tem importante função no desenvolvimento da cultura, visto que é o nutriente absorvido em maior quantidade pelo milho, além de ser constituinte de proteínas, ácidos nucléicos, citocromos e clorofila (Neptune et al., 1982; Cantarella et al., 2005; Costa et al., 2005). Normalmente, aplica-se uma pequena quantidade de $\mathrm{N}$ na semeadura do milho (30\% do total ou menos) e, posteriormente, uma quantidade maior em cobertura, visando evitar a concentração de sais no sulco de semeadura e, principalmente, a perda por lixiviação (Cantarella et al., 2005). Em geral, a adubação de cobertura tem sido realizada quando as plantas de milho apresentam de três a cinco folhas completamente expandidas (Fancelli \& Dourado-Neto, 2000).

Por outro lado, na prática agrícola, nem sempre é possivel adotar todas as recomendações agrícolas; nesse caso, a aplicação de herbicidas e a realização da cobertura nitrogenada, por vezes, podem ocorrer em um intervalo muito curto de tempo. Devine et al. (1993) mencionam que determinados herbicidas influenciam algumas rotas metabólicas das culturas, rotas estas que estão direta ou indiretamente relacionadas ao metabolismo de N.

Já foram observadas interações significativas entre a taxa de fertilização com $\mathrm{N}$ e a eficácia de herbicidas sobre plantas daninhas (Cathcart \& Swanton, 2004). Contudo, poucos trabalhos foram conduzidos de modo a relacionar a aplicação de $\mathrm{N}$ em cobertura e a seletividade de herbicidas às culturas. Dessa forma, foram conduzidos dois experimentos com o objetivo de estudar as conseqüências da adoção de diferentes fontes e épocas de adubação nitrogenada de cobertura sobre a seletividade de herbicidas aplicados em pósemergência na cultura do milho.

\section{MATERIAL E MÉTODOS}

Dois experimentos foram conduzidos em área experimental pertencente à Escola Superior de Agricultura "Luiz de Queiroz", situada no município de Piracicaba - SP (47³8'00" longitude oeste; $22^{\circ} 42^{\prime} 30^{\prime \prime}$ latitude sul), na Fazenda 'Areão', entre os meses de fevereiro e junho de 2004. A cultura do milho foi conduzida em condição de "safrinha", em área sem irrigação e com preparo convencional do solo. O solo da área é classificado como Nitossolo Vermelho Eutroférrico Latossólico (Embrapa, 1999), de textura argilosa e com as propriedades químicas apresentadas na Tabela 1.

A partir da análise química do solo e das recomendações da literatura visando produtividade entre 6 e $8 \mathrm{t} \mathrm{ha}^{-1}$, aplicaram-se $350 \mathrm{~kg} \mathrm{ha}^{-1}$ do adubo formulado 08-28-16 como adubação de base (Raij \& Cantarella, 1996). A semeadura do híbrido AGN 2012 foi feita em 2 de fevereiro de 2004, com uma máquina pneumática, alcançando uma densidade 
Tabela 1 - Análise química do solo da área experimental. Piracicaba, 2004

\begin{tabular}{|c|c|c|c|c|c|c|c|c|c|c|c|c|c|}
\hline $\mathrm{pH}$ & M.O. & $\mathrm{P}$ & $\mathrm{S}$ & $\mathrm{K}$ & $\mathrm{Ca}$ & $\mathrm{Mg}$ & $\mathrm{Al}$ & $\mathrm{H}+\mathrm{Al}$ & $\mathrm{SB}$ & $\mathrm{T}$ & $\mathrm{V}$ & $\mathrm{m}$ \\
\hline$\left(\mathrm{CaCl}_{2}\right)$ & $\left(\mathrm{g} \mathrm{dm}^{-3}\right)$ & \multicolumn{1}{|c|}{$\left.(\mathrm{mg} \mathrm{dm})^{-3}\right)$} & \multicolumn{6}{|c|}{$\left(\mathrm{mmolc} \mathrm{dm}^{-3}\right)$} & \multicolumn{2}{c|}{$\%$} \\
\hline 5,5 & 24 & 44 & 28 & 9,5 & 67 & 31 & 0 & 28 & 107 & 135 & 79 & 0 \\
\hline
\end{tabular}

$\mathrm{S}=\mathrm{NH}_{4}$ OAc $0,5 \mathrm{~N}$ em HOAc $0,25 \mathrm{~N}(10 \mathrm{~mL}$ TFSA/25 mL). Análise realizada pelo Departamento de Solos e Nutrição de Plantas da ESALQ/USP.

final de 60.000 plantas ha-1, após desbaste. As plantas emergiram entre 7 e 8 de fevereiro de 2004 e o desbaste foi realizado no dia 14 do mesmo mês. Os dados meteorológicos referentes ao período em que a cultura esteve a campo estão apresentados na Tabela 2 e foram obtidos no posto meteorológico do Departamento de Ciências Exatas da ESALGUSP, localizado a aproximadamente $3.000 \mathrm{~m}$ do experimento.

O delineamento experimental utilizado, em ambos os experimentos, foi o de blocos ao acaso, em esquema fatorial $4 \times 4$. As unidades experimentais constaram de cinco linhas da cultura, espaçadas de $0,8 \mathrm{~m}$, com quatro metros de comprimento, o que totalizou $16 \mathrm{~m}^{2} \mathrm{de}$ área total. Todas as parcelas foram mantidas sem a presença de plantas daninhas durante todo o experimento, por meio de capinas manuais. Foram realizadas, também, duas aplicações de delthametrina a $5 \mathrm{~g} \mathrm{ha}^{-1}$ para controle da lagarta-do-catucho (Spodoptera frugiperda), sendo a primeira quando a cultura apresentava duas folhas expandidas e a segunda com oito folhas expandidas.

Os tratamentos utilizados nos experimentos foram conseqüência da combinação fatorial entre quatro níveis do fator herbicida ( $\left.\mathrm{g} \mathrm{ha}^{-1}\right)$ : mesotrione (144) + atrazine (1.500) + Assist a 0,5\% v/v, foramsulfuron (45) + iodosulfuron (3) + Hoefix a $0,5 \% \mathrm{v} / \mathrm{v}$, nicosulfuron (20) + atrazine (1.500) + Assist a $0,5 \% \mathrm{v} / \mathrm{v}$ e testemunha capinada; e quatro níveis do fator época de adubação do fertilizante nitrogenado: 7, 3 e 0 dias antes e 7 dias após a aplicação dos herbicidas (DAA), totalizando 16 tratamentos.

Em um dos experimentos utilizou-se uréia incorporada como fonte nitrogenada e, no outro, sulfato de amônio a lanço. A uréia foi aplicada em dose proporcional a $150 \mathrm{~kg} \mathrm{ha}^{-1}$
(67,5 $\left.\mathrm{kg} \mathrm{N} \mathrm{ha}^{-1}\right)$, espalhada em um sulco com aproximadamente $0,05 \mathrm{~m}$ de profundidade, a $0,10 \mathrm{~m}$ de distância do caule das plantas de milho. Após a distribuição da uréia, o sulco foi fechado, caracterizando a adubação de cobertura com incorporação. O sulfato de amônio foi aplicado em dose proporcional a $300 \mathrm{~kg} \mathrm{ha}^{-1}$ (63 $\left.\mathrm{kg} \mathrm{N} \mathrm{ha}^{-1}\right)$, a lanço, em área total.

Os tratamentos herbicidas foram aplicados ao experimento em 23 de fevereiro de 2004, entre 9 h30 e 1 1h30. No instante da aplicação, a velocidade do vento oscilava entre $4 \mathrm{e}$ $6 \mathrm{~km} \mathrm{~h}^{-1}$, a temperatura do ar era de $20{ }^{\circ} \mathrm{C}$, a umidade relativa do ar era de $92 \%$ e o céu estava levemente encoberto, com aproximadamente $15 \%$ de nuvens. As aplicações foram feitas com auxílio de um pulverizador costal pressurizado por $\mathrm{CO}_{2}$, com pressão constante de 2,5 bar. A barra de aplicação contava com quatro bicos do tipo leque, modelo Teejet XL $110.02 \mathrm{VS}$, calibrado para um volume de calda proporcional a $200 \mathrm{~L} \mathrm{ha}^{-1}$. Na ocasião da aplicação, as plantas de milho apresentavam de quatro a cinco folhas expandidas.

Tabela 2 - Médias mensais de temperatura e umidade relativa do ar e totais mensais de precipitação e radiação solar global total. Piracicaba, 2004

\begin{tabular}{|l|c|c|c|c|}
\hline \multirow{2}{*}{ Mês/2004 } & $\mathrm{T}^{1 /}$ & $\mathrm{UR}^{2 /}$ & Rad.Glob. $^{3 /}$ & Precipitação \\
\cline { 2 - 5 } & $\left({ }^{\circ} \mathrm{C}\right)$ & $(\%)$ & $\left(\mathrm{MJ} \mathrm{m}^{-2} \mathrm{~d}^{-1}\right)$ & $(\mathrm{mm})$ \\
\hline Fevereiro & 22,8 & 80,2 & 549,2 & 193,7 \\
\hline Março & 22,4 & 78,3 & 595,2 & 79,0 \\
\hline Abril & 22,0 & 80,9 & 473,2 & 87,7 \\
\hline Maio & 17,7 & 89,2 & 361,9 & 107,9 \\
\hline Junho & 17,0 & 87,1 & 327,1 & 50,6 \\
\hline Julho & 16,8 & 85,7 & 347,4 & 77,4 \\
\hline Total & - & - & $2.653,9$ & 596,3 \\
\hline
\end{tabular}

1/ Temperatura média; $\stackrel{2}{2}$ umidade relativa média do ar; $\stackrel{2}{\text { radiação }}$ solar global total. 
As variáveis avaliadas foram: fitotoxicidade aos 7, 14, 21 e 28 DAA; altura das plantas de milho por ocasião do florescimento; massa de 1.000 grãos; e rendimento (t ha ${ }^{-1}$ ). A fitotoxicidade foi avaliada por meio de uma escala percentual de danos causados à morfologia das plantas de milho, variando entre 0 (ausência de danos) e 100\% (morte das plantas). A medição de altura das plantas ocorreu aos 70 dias após emergência (florescimento), medindo-se dez plantas por parcela, do nível do solo à base da panícula em floração.

A colheita da cultura foi feita em 23 de junho de 2004. O rendimento foi estimado pela colheita das duas linhas centrais da parcela, deixando $0,5 \mathrm{~m}$ de bordadura, o que totalizou a área útil de $4,8 \mathrm{~m}^{2}$. As espigas foram despalhadas e debulhadas mecanicamente, de forma a separar os grãos de cada parcela, os quais foram pesados. Nesse momento, cada amostra teve sua umidade mensurada, a qual serviu para correção da massa total de grãos por parcela para $14 \%$ de umidade. De cada parcela, uma amostra de 1.000 grãos foi retirada, pesada e também teve sua umidade corrigida para $14 \%$.
O dados foram analisados estatisticamente através da aplicação do teste $\mathrm{F}$ sobre a análise da variância, seguida da aplicação de teste de Tukey (5\%) para comparação das médias. Em ambas as análises adotou-se o nível de significância de $5 \%$. Os dados de porcentagem foram transformados, quando necessário, visando alcançar a distribuição normal e a homogeneidade de variâncias.

\section{RESULTADOS E DISCUSSÃO}

No experimento que envolveu a uréia como fonte nitrogenada, não foram detectadas interações significativas entre os tratamentos com herbicidas e os intervalos de aplicação da cobertura nitrogenada sobre as variáveis de fitotoxicidade (qualquer avaliação), altura de plantas, massa de 1.000 grãos ou rendimento (Tabelas 3 e 4). Essa condição evidencia que todos os tratamentos herbicidas apresentaram comportamentos semelhantes diante dos diferentes intervalos de aplicação da cobertura.

Foram observados efeitos significativos isolados dos tratamentos herbicidas sobre a fitotoxicidade aos $7,14,21$ e 28 DAA e

Tabela 3 - Fitotoxicidade resultante dos tratamentos herbicidas e dos diferentes intervalos de aplicação de uréia incorporada. Piracicaba, 2004

\begin{tabular}{|c|c|c|c|c|c|}
\hline \multirow{2}{*}{ Herbicida } & \multirow{2}{*}{$\frac{\text { Dose }}{\left(\mathrm{g} \mathrm{ha}^{-1}\right)}$} & \multicolumn{4}{|c|}{ Fitotoxicidade (\%) } \\
\hline & & $7 \mathrm{DAA}^{1 /}$ & 14 DAA & $21 \mathrm{DAA}$ & 28 DAA \\
\hline mesotrione + atrazina & $144+1.500$ & $2,75 \mathrm{a}$ & $3,23 \mathrm{~b}$ & $0,94 \mathrm{ab}$ & $0,13 \mathrm{a}$ \\
\hline nicosulfuron + atrazina & $20+1.500$ & $12,25 \mathrm{~b}$ & $5,81 \mathrm{~b}$ & $2,69 \mathrm{~b}$ & $1,13 \mathrm{~b}$ \\
\hline foramsulfuron + iodosulfuron & $45+3$ & $8,31 \mathrm{~b}$ & $3,50 \mathrm{~b}$ & $1,50 \mathrm{ab}$ & $0,19 \mathrm{a}$ \\
\hline testemunha & - & $0,00 \mathrm{a}$ & $0,00 \mathrm{a}$ & $0,00 \mathrm{a}$ & $0,00 \mathrm{a}$ \\
\hline Uréia & $\left(\mathrm{kg} \mathrm{ha}^{-1}\right)$ & \multicolumn{4}{|c|}{ Fitotoxicidade (\%) } \\
\hline 7 dias antes & 150 & $5,50 \mathrm{ab}$ & $4,13 \mathrm{a}$ & $1,69 \mathrm{a}$ & $0,50 \mathrm{a}$ \\
\hline 3 dias antes & 150 & $4,06 \mathrm{a}$ & $1,69 \mathrm{a}$ & $0,63 \mathrm{a}$ & $0,13 \mathrm{a}$ \\
\hline 0 dias & 150 & $9,00 \mathrm{~b}$ & $3,81 \mathrm{a}$ & $1,94 \mathrm{a}$ & $0,69 \mathrm{a}$ \\
\hline 7 dias depois & 150 & $4,75 \mathrm{ab}$ & $2,94 \mathrm{a}$ & $0,86 \mathrm{a}$ & $0,13 \mathrm{a}$ \\
\hline Fator & & \multicolumn{4}{|c|}{ Parâmetro estatístico } \\
\hline F herbicida $(\mathrm{H})$ & & $23,70^{*}$ & $8,52 *$ & $4,80 *$ & $5,83 *$ \\
\hline F Uréia & & $3,77 *$ & $1,78^{\mathrm{ns}}$ & $1,51^{\mathrm{ns}}$ & $1,73^{\mathrm{ns}}$ \\
\hline F H x Uréia & & $1,07^{\mathrm{ns}}$ & $0,55^{\mathrm{ns}}$ & $0,56^{\mathrm{ns}}$ & $1,05^{\mathrm{ns}}$ \\
\hline DMS herbicida & & 4,27 & 3,09 & 1,93 & 0,81 \\
\hline DMS Uréia & & 4,27 & 3,09 & 1,93 & 0,81 \\
\hline
\end{tabular}

1' DAA: dias após aplicação do herbicida. Médias seguidas da mesma letra nas colunas não diferem significativamente pelo teste Tukey a $5 \%$.

* significativo pelo teste $\mathrm{F}$ a $5 \%$ de probabilidade. ${ }^{\mathrm{ns}}$ não-significativo pelo teste $\mathrm{F}$ a $5 \%$ de probabilidade. 
Tabela 4 - Altura de plantas, rendimento de grãos e massa de 1.000 grãos resultantes dos diferentes tratamentos herbicidas e dos diferentes intervalos de aplicação de uréia incorporada. Piracicaba, 2004

\begin{tabular}{|c|c|c|c|c|}
\hline \multirow{2}{*}{ Herbicida } & Dose & Altura de plantas & Rendimento de grãos & Massa de 1.000 grãos \\
\hline & $\left(\mathrm{g} \mathrm{ha}^{-1}\right)$ & $(\mathrm{m})$ & $\left(\mathrm{t} \mathrm{ha}^{-1}\right)$ & $(\mathrm{g})$ \\
\hline mesotrione + atrazina & $144+1.500$ & $2,19 \mathrm{a}$ & $5,55 \mathrm{a}$ & $353,61 \mathrm{a}$ \\
\hline nicosulfuron + atrazina & $20+1.500$ & $2,20 \mathrm{a}$ & $5,67 \mathrm{a}$ & $348,62 \mathrm{a}$ \\
\hline foramsulfuron + iodosulfuron & $45+3$ & $2,19 \mathrm{a}$ & $5,52 \mathrm{a}$ & $342,39 \mathrm{a}$ \\
\hline testemunha & - & $2,24 \mathrm{a}$ & $5,77 \mathrm{a}$ & $355,94 \mathrm{a}$ \\
\hline Uréia & $\left(\mathrm{kg} \mathrm{ha}^{-1}\right)$ & Altura de plantas & Rendimento de grãos & Massa de 1.000 grãos \\
\hline 7 dias antes & 150 & $2,21 \mathrm{a}$ & $5,51 \mathrm{a}$ & $351,77 \mathrm{a}$ \\
\hline 3 dias antes & 150 & $2,20 \mathrm{a}$ & $5,86 \mathrm{a}$ & $355,13 \mathrm{a}$ \\
\hline 0 dias & 150 & $2,21 \mathrm{a}$ & $5,54 \mathrm{a}$ & $347,03 \mathrm{a}$ \\
\hline 7 dias depois & 150 & $2,21 \mathrm{a}$ & $5,60 \mathrm{a}$ & $346,63 \mathrm{a}$ \\
\hline Fator & & & estatístico & \\
\hline F herbicida $(\mathrm{H})$ & & $1,33^{\mathrm{ns}}$ & $0,29^{\mathrm{ns}}$ & $1,47^{\mathrm{ns}}$ \\
\hline F Uréia & & $0,03^{\mathrm{ns}}$ & $0,56^{\mathrm{ns}}$ & $0,67^{v}$ \\
\hline F H x Uréia & & $0,48^{\mathrm{ns}}$ & $0,76^{\mathrm{ns}}$ & $1,19^{v}$ \\
\hline DMS herbicida & & 0,07 & 0,82 & 18,68 \\
\hline DMS Uréia & & 0,07 & 0,82 & 18,68 \\
\hline $\mathrm{CV}(\%)$ & & 3,47 & 15,43 & 5,65 \\
\hline
\end{tabular}

Médias seguidas da mesma letra nas colunas não diferem significativamente pelo teste de Tukey a 5\%. ${ }^{\text {ns }}$ não-significativo pelo teste $\mathrm{F}$ a $5 \%$ de probabilidade.

dos intervalos de aplicação da cobertura nitrogenada somente aos 7 DAA (Tabela 3). Aos 7 DAA, os tratamentos nicosulfuron + atrazina e foramsulfuron + iodosulfuron provocaram os maiores efeitos fitotóxicos. Ainda nesse período, observou-se que a adubação com uréia no dia da aplicação dos herbicidas provocou os maiores valores de fitotoxicidade $(9,0 \%)$, porém esse valor não diferiu da aplicação do insumo aos sete dias antes ou aos sete dias após a aplicação dos herbicidas.

Os sintomas fitotóxicos diminuíram com o decorrer das avaliações, mostrando que o híbrido utilizado apresentou grande capacidade em detoxificar as moléculas herbicidas absorvidas. Contudo, segundo López Ovejero (2000) e Damião-Filho et al. (1996), mesmo quando os sintomas de fitotoxicidade no milho não são aparentes, ainda podem ocorrer reduções no rendimento final da cultura.

Na Tabela 4, observa-se que não ocorreram efeitos isolados dos tratamentos herbicidas ou dos diferentes intervalos de aplicação da cobertura nitrogenada sobre as variáveis altura de plantas, rendimento e massa de 1.000 grãos. Com os valores da altura de plantas no florescimento, confirmam-se as observações de fitotoxicidade, mostrando que, independentemente de algumas lesões iniciais em função de cada tratamento, as plantas de milho foram capazes de metabolizar os herbicidas, atingindo altura de pendoamento homogênea. A partir dos dados de massa de 1.000 grãos e rendimento, comprova-se, novamente, a ausência de efeito dos tratamentos sobre a cultura.

Os resultados encontrados neste experimento, para os herbicidas mesotrione + atrazina, concordam com aqueles observados por Mascarenhas (2004), que testou a aplicação no mesmo dia de uréia e mesotrione + atrazina + óleo. Nessa situação, foi observado que os híbridos de milho BRS 1010, BRS 3151 e DOW 8550, apesar de manifestarem fitotoxicidade inicial, não apresentaram redução de rendimento de grãos quando comparados com a testemunha capinada.

No experimento que envolveu sulfato de amônio também não ocorreram interações significativas entre os efeitos dos tratamentos com herbicidas e os intervalos de aplicação da cobertura nitrogenada sobre as variáveis fitotoxicidade, altura de plantas, massa de 1.000 grãos e rendimento (Tabelas 5 e 6). Essa 
Tabela 5 - Fitotoxicidade resultante dos tratamentos herbicidas e dos diferentes intervalos de aplicação de adubações de cobertura com sulfato de amônio. Piracicaba, 2004

\begin{tabular}{|c|c|c|c|c|c|}
\hline \multirow{2}{*}{ Herbicida } & Dose & \multicolumn{4}{|c|}{ Fitotoxicidade (\%) } \\
\hline & $\left(\mathrm{g} \mathrm{ha}^{-1}\right)$ & $7 \mathrm{DAA}^{1 /}$ & 14 DAA & $21 \mathrm{DAA}$ & 28 DAA \\
\hline mesotrione + atrazina & $144+1.500$ & $5,00 \mathrm{ab}$ & $3,19 a b$ & $1,06 \mathrm{a}$ & $0,13 \mathrm{a}$ \\
\hline nicosulfuron + atrazina & $20+1.500$ & $9,12 \mathrm{bc}$ & $4,69 \mathrm{~b}$ & $2,13 \mathrm{a}$ & $0,88 \mathrm{a}$ \\
\hline foramsulfuron + iodosulfuron & $45+3$ & $11,12 \mathrm{c}$ & $4,56 \mathrm{~b}$ & $1,81 \mathrm{a}$ & $0,75 \mathrm{a}$ \\
\hline testemunha & - & $1,00 \mathrm{a}$ & $1,06 \mathrm{a}$ & $0,31 \mathrm{a}$ & $0,00 \mathrm{a}$ \\
\hline Sulfato de Amônio & $\left(\mathrm{kg} \mathrm{ha}^{-1}\right)$ & \multicolumn{4}{|c|}{ Fitotoxicidade (\%) } \\
\hline 7 dias antes & 300 & 8,06 a & $3,38 \mathrm{a}$ & $1,13 \mathrm{a}$ & $0,44 \mathrm{a}$ \\
\hline 3 dias antes & 300 & 7,13 a & $4,06 \mathrm{a}$ & $2,25 \mathrm{a}$ & $0,88 \mathrm{a}$ \\
\hline 0 dias & 300 & $7,13 \mathrm{a}$ & $3,06 \mathrm{a}$ & $0,81 \mathrm{a}$ & $0,13 \mathrm{a}$ \\
\hline 7 dias depois & 300 & $3,94 \mathrm{a}$ & $3,00 \mathrm{a}$ & $1,13 \mathrm{a}$ & $0,31 \mathrm{a}$ \\
\hline Fator & & \multicolumn{4}{|c|}{ Parâmetro estatístico } \\
\hline F herbicida $(\mathrm{H})$ & & $10,76^{*}$ & $3,53 *$ & $2,23 *$ & $2,11^{\mathrm{ns}}$ \\
\hline F sulfato de amônio (AS) & & $1,73^{\mathrm{ns}}$ & $0,29^{\mathrm{ns}}$ & $1,35^{\mathrm{ns}}$ & $1,11^{\mathrm{ns}}$ \\
\hline F H x AS & & $0,43^{\text {ns }}$ & $0,44^{\text {ns }}$ & $0,77^{\mathrm{ns}}$ & $0,73^{\text {ns }}$ \\
\hline DMS herbicida & & 5,18 & 3,39 & 2,05 & 1,14 \\
\hline DMS sulfato de amônio & & 5,18 & 3,39 & 2,05 & 1,14 \\
\hline
\end{tabular}

1/ DAA: dias após aplicação do herbicida. Médias seguidas da mesma letra nas colunas não diferem significativamente pelo teste de Tukey a 5\%. * significativo pelo teste $\mathrm{F}$ a $5 \%$ de probabilidade. ${ }^{\text {ns }}$ não-significativo pelo teste $\mathrm{F}$ a $5 \%$ de probabilidade.

Tabela 6 - Altura de plantas, rendimento de grãos e massa de 1.000 grãos resultantes dos diferentes tratamentos herbicidas e dos diferentes intervalos de aplicação de adubações de cobertura com sulfato de amônio. Piracicaba, 2004

\begin{tabular}{|c|c|c|c|c|}
\hline \multirow{2}{*}{ Herbicida } & Dose & Altura de plantas & Rendimento de grãos & Massa de 1.000 grãos \\
\hline & $\left(\mathrm{g} \mathrm{ha}^{-1}\right)$ & $(\mathrm{m})$ & $\left(\mathrm{t} \mathrm{ha}^{-1}\right)$ & $(\mathrm{g})$ \\
\hline mesotrione + atrazina & $144+1.500$ & $2,21 \mathrm{a}$ & $5,93 \mathrm{a}$ & $354,16 \mathrm{a}$ \\
\hline nicosulfuron + atrazina & $20+1.500$ & $2,19 \mathrm{a}$ & $5,94 \mathrm{a}$ & $345,59 \mathrm{a}$ \\
\hline foransulfuron + iodosulfuron & $45+3$ & $2,20 \mathrm{a}$ & $5,93 \mathrm{a}$ & $343,63 \mathrm{a}$ \\
\hline testemunha & - & $2,20 \mathrm{a}$ & $6,10 \mathrm{a}$ & $346,41 \mathrm{a}$ \\
\hline Sulfato de Amônio & $\left(\mathrm{kg} \mathrm{ha}^{-1}\right)$ & & & \\
\hline 7 dias antes & 300 & $2,20 \mathrm{a}$ & $5.68 \mathrm{a}$ & $350,48 \mathrm{a}$ \\
\hline 3 dias antes & 300 & $2,20 \mathrm{a}$ & $5,72 \mathrm{a}$ & $351,19 \mathrm{a}$ \\
\hline 0 dias & 300 & $2,21 \mathrm{a}$ & $6,14 \mathrm{a}$ & $341,96 \mathrm{a}$ \\
\hline 7 dias depois & 300 & $2,19 \mathrm{a}$ & $6,36 \mathrm{a}$ & $346,14 \mathrm{a}$ \\
\hline Fator & & & Parâmetro estatístico & \\
\hline F herbicida $(\mathrm{H})$ & & $0,72^{\mathrm{ns}}$ & $0,22^{\mathrm{ns}}$ & $0,79^{\mathrm{ns}}$ \\
\hline F Sulfato de Amônio (SA) & & $0,94^{\mathrm{ns}}$ & $3,38^{*}$ & $0,68^{\mathrm{ns}}$ \\
\hline FHxAS & & $0,60^{\text {ns }}$ & $0,15^{\text {ns }}$ & $1,05^{\mathrm{ns}}$ \\
\hline DMS herbicida & & 0,04 & 0,69 & 19,63 \\
\hline DMS Sulfato de Amônio & & 0,04 & 0,69 & 19,63 \\
\hline CV $(\%)$ & & 1,87 & 12,19 & 5,99 \\
\hline
\end{tabular}

Médias seguidas da mesma letra nas colunas não diferem pelo teste de Tukey a 5\%. * significativo pelo teste $\mathrm{F}$ a $5 \%$ de probabilidade.

${ }^{\text {ns }}$ não-significativo pelo teste $\mathrm{F}$ a $5 \%$ de probabilidade. 
análise evidencia, também para o sulfato de amônio, que todos os tratamentos herbicidas mostraram comportamentos semelhantes diante dos diferentes intervalos de aplicação da adubação de cobertura.

Neste experimento, foram observados efeitos isolados dos tratamentos herbicidas somente para a variável fitotoxicidade aos 7 e 14 DAA (Tabela 5). Aos 7 DAA, os tratamentos de nicosulfuron + atrazina e foramsulfuron + iodosulfuron foram os que provocaram os maiores efeitos fitotóxicos. Os sintomas tornaram-se menos evidentes com o decorrer do tempo, de modo que aos 28 DAA praticamente não foram perceptíveis. Não foi observado efeito dos intervalos de aplicação do sulfato de amônio sobre as variáveis avaliadas.

A aplicação do fertilizante (sulfato de amônio) a lanço promoveu injúrias provenientes do contato físico do fertilizante com a superfície foliar. Contudo, esses sintomas não indicam a ocorrência de interação entre o sulfato de amônio e os herbicidas, pois dentro das épocas de aplicação não há diferenças significativas

Não foram observados efeitos isolados dos tratamentos herbicidas ou dos diferentes intervalos de aplicação da cobertura nitrogenada com sulfato de amônio sobre as variáveis altura de plantas, rendimento e massa de 1.000 grãos (Tabela 6). Mais uma vez, os dados de altura de plantas não indicaram nenhuma redução proveniente dos danos fitotóxicos. Os dados de massa de 1.000 grãos de milho e o rendimento obtido para cada tratamento não mostraram reduções quando comparados com os das testemunhas capinadas dentro de cada intervalo e entre os intervalos. Dessa forma, ressalta-se que não foram observados efeitos de interação do sulfato de amônio com nenhum dos herbicidas nas condições em que o experimento foi conduzido; esses resultados foram considerados semelhantes àqueles obtidos no experimento com uréia.

Fleck et al. (2001) testaram os efeitos dos herbicidas atrazina e amônio-glufosinate na absorção do nitrogênio e em características das plantas de milho. Nesse estudo, os autores não observaram interação entre os herbicidas aplicados e as fontes de nitrogênio, de forma que o uso destes herbicidas, em doses reduzidas (abaixo das recomendadas), aplicados isoladamente ou combinados, não afetou os componentes do rendimento da cultura.

Ressalta-se, porém, que durante o ano agrícola em que foram conduzidos os experimentos ocorreram precipitações e temperaturas adequadas para o crescimento e desenvolvimento da cultura (Tabela 2). Essas variáveis meteorológicas podem ter desfavorecido a interação dos tratamentos herbicidas com os diferentes intervalos da cobertura, que, aliada às características do híbrido (duplo), contribuiu para a recuperação das plantas, provavelmente devido à manutenção da adequada atividade metabólica do milho.

Conclui-se que, nas condições em que os ensaios foram realizados, não ocorreram interações entre os tratamentos herbicidas e os intervalos de aplicação da cobertura nitrogenada (uréia ou sulfato de amônio) em relação à aplicação dos herbicidas, para o híbrido de milho AGN 2012.

\section{LITERATURA CITADA}

ABDIN, O. A. et al. Cover crops and interrow tillage for weed control in short season maize (Zea mays). Eur. J. Agron., v. 12, p. 93-102, 2000.

CANTARELLA, H.; DUARTE, A. P.; ANDRADE, C. A. Manejo de nitrogênio e de materia orgânica em milho no sistema plantio direto. In: FANCELLI, A. L.; DOURADO NETO, D. (Eds.). Milho: tecnologia \& produção. Piracicaba: Escola Superior de Agricultura "Luiz de Queiroz”, 2005. p. 59-82.

CATHCART, R. J.; SWANTON, C. J. Fertilizer nitrogen rate and the response of weeds to herbicides. Weed Sci., v. 52, p. 291-296, 2004.

CHRISTOFFOLETI, P. J.; MENDONÇA, C. G. Controle de plantas daninhas na cultura de milho: enfoque atual. In: FANCELLI, A. L.; DOURADO-NETO, D. (Coords.). Milho: tecnologia e produtividade. Piracicaba: Escola Superior de Agricultura "Luiz de Queiroz", 2001. p. 60-95.

COSTA, F. M. P. et al. Nitrogênio e produtividade de grãos de milho. In: FANCELLI, A. L.; DOURADO NETO, D. (Eds.). Milho: tecnologia \& produção. Piracicaba: Escola Superior de Agricultura "Luiz de Queiroz", 2005. p. 118-128. 
DAMIÃO FILHO, C. F.; MÔRO, F. V.; TAVEIRA, L. R. Respostas de híbridos de milho ao nicosulfuron. I - Aspectos biológico e da produção. Planta Daninha, v. 14, p. 3-13, 1996.

DEVINE, M.; DUKE, S. O.; FEDTKE, C. Physiology of herbicide action. Englewood Cliffs: PTR Prentice Hall, 1993. $441 \mathrm{p}$.

EMPRESA BRASILEIRA DE PESQUISA AGROPECUÁRIA - EMBRAPA. Sistema brasileiro de classificação de solos. Brasília, 1999. 412 p.

FANCELLI, A. L.; DOURADO-NETO, D. Produção de milho. Guaíba: Agropecuária, 2000. 360 p.

FLECK, N. G. et al. Ação dos herbicidas atrazina e glufosinate de amônio no aproveitamento de nitrogênio pelas plantas de milho. Planta Daninha, v. 19, p. 235-245, 2001.

JAKELAITIS, A. et al. Efeitos de herbicidas no consórcio de milho com Brachiaria brizantha. Planta Daninha, v. 23, p. 69-78, 2005.

LÓPEZ OVEJERO, R. F. Desempenho da cultura de milho (Zea mays) submetida a diferentes herbicidas na ausência de plantas daninhas. 2000. $46 \mathrm{f}$. Dissertação (Mestrado em Agronomia) - Escola Superior de Agricultura "Luiz de Queiroz", Piracicaba, 2000.
LÓPEZ OVEJERO, R. F. et al. Manejo de plantas daninhas na cultura do milho. In: FANCELLI, A. L.; DOURADONETO, D. (Eds.). Milho: estratégias de manejo para alta produtividade. Piracicaba: Escola Superior de Agricultura "Luiz de Queiroz", 2003. p. 47-79.

MASCARENHAS, M. H. T. Eficácia e seletividade do mesotrione + (atrazine+ óleo vegetal) sobre híbridos de milho associado à época de aplicação do fertilizante nitrogenado.

B. Inf. Soc. Bras. Ci. Plantas Daninhas, v. 10, p. 132, 2004. (Suplemento)

NEPTUNE, A. M. L. et al. Efeitos de doses nãoeqüidistantes de $\mathrm{N}, \mathrm{P}, \mathrm{K}$ nas concentrações destes macronutrientes na folha e na produção do milho (Zea mays). An. ESALQ, v. 39, p. 917-941, 1982.

RAIJ, B. van; CANTARELLA, H. Milho para grãos e silagens. In. RAIJ, B. V. et al. (Eds.). Adubação no estado de São Paulo. Campinas: IAC, 1996. p. 56-59. (Boletim Técnico, 100)

WILSON, R. G. Effect of preplant tillage, post-plant cultivation and herbicides on weed density in corn. Weed Technol., v. 7, p. 728-734, 1993.

ZAGONEL, J.; VENÂNCIO, W. S.; KUNZ, R. P. Efeitos de métodos e épocas de controle das plantas daninhas na cultura do milho. Planta Daninha, v. 18, p. 143-150, 2000. 